\title{
Press coverage of public expenditure of Master Settlement Agreement funds: how are non-tobacco control related expenditures represented?
}

\author{
K M Clegg Smith, M A Wakefield, M Nichter
}

See end of article for authors' affiliations .....................

Correspondence to: Katherine M Clegg Smith, 850 W. Jackson Blvd, Suite 400 Chicago, IL 60607, USA kmcsmith@uic.edu

Received

7 October 2002

Accepted 25 March 2003

\begin{abstract}
Objective: To examine newspaper reports of Master Settlement Agreement (MSA) allocation decisions outside of tobacco control, focusing on the arguments being put forth in favour of competing claims on MSA funds. The major aims were to identify newsworthy non-tobacco control areas for which MSA funds have been applied and to examine how non-tobacco control spending has been presented through the US press.

Design: A qualitative textual analysis was performed on 94 articles taken from a sample of 322 newspapers over a 12 month period (October 2000 through September 2001) that related to the allocation of MSA funds to non-tobacco control causes. Articles were coded for general content areas of MSA allocation as well as for rhetorical and framing devices employed to explain and justify allocation decisions.

Main outcome measures: (1) Areas of non-tobacco control allocation; (2) rhetorical devices and framing techniques employed in the articles to discuss the allocation.

Results: The analysis identified a wide variety of issues for which MSA funds were being appropriated. Three main frames emerged in relation to justifying or appealing for particular spending decisions: (1) funds should be allocated to the needy and/or the deserving; (2) funds should be spent on state development; (3) funds should be put towards helping the state weather a crisis. Claims for each such issue were made using strategies such as presenting the MSA funds as a "windfall", focusing coverage on the merits of the cause rather than the issue of resource allocation, and stressing links between the particular claim and the stated objectives of the MSA.

Conclusions: Press coverage of MSA non-tobacco control spending suggests that the funds have been quickly formulated as fodder for state spending, rather than to support tobacco control efforts. Thus, caution is required in pursuing settlements with the industry where the objective is better funding for tobacco control efforts, particularly in light of the possibility that press coverage of MSA allocation may actually serve as positive publicity for the tobacco industry.
\end{abstract}

n November 1998, attorneys general of 46 US states signed the Master Settlement Agreement (MSA) with the major US tobacco companies. Through this agreement, provisions were made such that the tobacco industry would recompense the states for smoking related health Medicaid expenses. Thus, over the 25 years following the MSA, the 46 signatory states are to receive an estimated $\$ 206$ billion from the companies.

Initially, the MSA was hailed by many in the tobacco control community as presenting a significant opportunity because of the additional resources that it would provide for prevention and cessation efforts. However, experience gained in the years immediately following the signing suggests that because there is no provision in the agreement as to how these funds should be spent, the MSA will provide only limited additional resources for tobacco control. Rather, it is disappointing for advocates to observe that the funds generated by the MSA have tended to be appropriated to other state and community level issues.

Only three states currently (as of mid 2002) allocate the recommended $20-25 \%$ of MSA funds to tobacco control programmes (the minimum recommended level as determined by the Centers for Disease Control and Prevention), and the majority of states actually allocate less than half of this. ${ }^{1}$ Unfortunately, this trend can only be expected to continue as state budgets become increasingly tight and it becomes more tempting for states to divert funds away from tobacco control and towards providing key state services and meeting budget- ary shortfalls. Although tobacco control advocates acknowledge having had limited success in gaining the desired level of funding allocation from the MSA funds for tobacco control purposes, there has not, as yet, been any systematic research published as to the arguments that have been used to appropriate funds for other purposes.

In this study, we conduct qualitative analysis of press coverage of state and local MSA allocation decisions as a means through which to understand better the competing claims that are being made for these funds. The news media is an immensely powerful and pervasive institution, both in the USA and around the globe. Indeed, the aggregate of all unpaid media coverage would routinely outweigh even the most intensive counter-advertising coverage. ${ }^{2}$ In particular, the news media's ability to choose, create, sustain, and shape an issue for public consumption is influential as to the ways in which issues are presented for consideration by the public. ${ }^{34}$ The news media provides ways of thinking about specific issues through the signs and symbols that are employed for definition. ${ }^{5}$ Thus, analyses regarding the framing of tobacco issues in the mass media may improve understanding of both the successes and limitations of public health efforts and campaigns in relation to tobacco. ${ }^{6}$ Knowing which particular issues receive press attention helps to understand change in public attitudes and behaviour, as well as the success or failure of policy initiatives. Furthermore, analyses of the news can improve our understanding of societal values and concerns at a given time, ${ }^{78}$ since the definition of what is newsworthy 
Table 1 Different types of projects identified in the press coverage for which MSA funds are being sought

\begin{tabular}{|c|c|}
\hline Proposed allocation & State/s \\
\hline Medicaid nursing home coverage & Arkansas \\
\hline Uninsured children & California \\
\hline Illicit drug prevention & Florida \\
\hline Capital projects (university buildings, research laboratories) & Virginia, Pennsylvania, Arkansas \\
\hline Reimbursement for hospital care for the uninsured & Massachusetts, Pennsylvania \\
\hline Laptop computers for legislators & New York \\
\hline Prescription drugs for the elderly & Pennsylvania, North Carolina, Missouri, Connecticut, North Carolina \\
\hline Cancer research & Maryland \\
\hline Medicaid funding & Mississippi \\
\hline Prescriptions for the uninsured & Pennsylvania \\
\hline Long term nursing home care & Pennsylvania \\
\hline Text books for parochial schools & Maryland \\
\hline School nurses & Arkansas \\
\hline Home care for the elderly & Pennsylvania \\
\hline Investigate foal death crisis & Kentucky \\
\hline Insurance for uninsured adults & Pennsylvania, New York \\
\hline Workers' health insurance & South Carolina \\
\hline Juvenile justice system & Alabama \\
\hline Nursing shortage & Pennsylvania \\
\hline Biotechnology labs & Pennsylvania \\
\hline State pay raises & Mississippi \\
\hline Children's services & Alabama \\
\hline Foster care & Alabama \\
\hline Balancing the budget & Mississippi, Massachusetts, South Carolina, North Carolina, Maine \\
\hline Asthma equipment in classrooms & New York \\
\hline Health care clinics & Montana \\
\hline Water systems & South Carolina \\
\hline Conservation programme & Kentucky \\
\hline Tax cuts/avoid tax increase & New York, Florida, South Carolina \\
\hline
\end{tabular}

entails both contemporary understanding of the significance of specific events, as well as commonly held perspectives on institutional behaviour and motives. ${ }^{9}$ The ideologies, assumptions, and connections that are called upon to frame important news stories are key to how issues are selected by and made salient to the audience. ${ }^{10}$

There are a growing number of public health studies ${ }^{11-16}$ that demonstrate both the impact of media coverage of particular issues in shaping individual level behaviours and attitudes, and also in influencing policy decisions. The news media is a powerful mechanism through which images of problems such as tobacco use are conveyed. ${ }^{17}$ Examining the framing of issues in the news can provide insight as to the successes and limitations of various public health campaigns such as those undertaken by tobacco control advocates. ${ }^{6} 10$

In conducting this analysis, we aim to identify and discuss the variety of initiatives on behalf of which different advocates are vying for MSA funds, focusing on the ways in which funding decisions are being presented and justified to the public. Given that the MSA funds were officially secured in order to reimburse states for tobacco related health costs, an analysis of how non-tobacco control claims are being publicly constructed is important for defending similar spending streams in the future.

\section{METHOD}

The data for this study comprise articles from US daily newspapers that deal with the allocation of MSA funds to causes that are not related to tobacco control. The articles were compiled from a sample of 322 daily newspapers that includes a range of major metropolitan, regional, town, and even small rural publications. The data collection is ongoing, but the articles in this study all pertain to one year's coverage (from 1 October 2000 to 30 September 2001) in which most states were engaged in some process of allocating the MSA funds.

From this year of data, we identified and coded 94 articles that discussed the allocation of MSA funds only to non-tobacco control issues. Only articles that mentioned the
MSA, but made no substantive reference to tobacco control, were included in this analysis. We focused in particular on identifying the reported areas of state MSA spending and the ways that the spending decisions were constructedparticularly the rhetorical devices being employed to make assertions on behalf of particular non-tobacco control causes. We understand "rhetoric" to be the persuasive argumentation that is accomplished through positioning and framing issues in ways which appeal to the practical logic of particular audiences (discursive communities). Rhetoric is a definitional practice which shapes, enables, and also limits how people think about things.

\section{RESULTS}

For which programmes or issues have MSA funds been sought?

Table 1 contains the different types of projects identified in the press coverage for which MSA funds are either being sought, or for which an agreement for allocation already exists and was being discussed in the press. This is not a comprehensive list of all of the issues that compete with tobacco control for MSA funding, but rather provides some insight into the range of such causes, particularly those considered worthy of press attention.

\section{What are the common themes in the claims being made on the MSA funds?}

The press coverage clearly presented a variety of different issues for which MSA funds were being claimed. At the same time, there were also common themes that ran through many of the articles, and across many of the substantive issues.

One observation was that the driving force behind much of the news coverage seemed to be to provide evidence in support of the prioritisation of funding for certain issues. Often, a particularly vulnerable subgroup such as children, the poor, the unemployed or the elderly were specified as being appropriate recipients of the "help" that could be provided through these funds. In such articles, the focus was clearly on the issue for 
which funds were being sought rather than on the MSA as the potential source of funding.

"Pennsylvanians who can't afford health insurance now may be able to secure coverage next year. The state is developing a plan to use part of its $\$ 11$ billion tobacco settlement to start dealing with uninsured adults . . The program will benefit uninsured adults 19 to 64 years old who haven't had coverage for at least 90 days before enrolling." - Scranton Tribune, Pennsylvania, 21 August 2001.

"\$650,000 grant to provide health insurance for kids. Santa Clara County's plan to provide health insurance to its 71,000 uninsured children has received its first grant . . .Most of the $\$ 7.5$ million raised for the program comes from the tobacco tax and tobacco settlement." Orange County Register, California, 15 April 2001.

Claims on the MSA funds on behalf of the "deserving" or the "needy" were portrayed as essentially unquestionable by framing the discussion in such a way as to draw upon the undeniable worth of particular causes. "Is our state government going to cut health care for the poor while it's rolling in tobacco cash?"-Paducah Sun, Kentucky, 2 February 2001. Articles promoted the exigency of a certain cause or group rather than the issue of the allocation itself. The following excerpt is typical of such articles for its description of the need for foster care funding.

"Children's services in this state, like many of the children dependent on them, are hurting badly." - Birmingham News, Alabama, 20 August 2001.

Articles focusing on the needy sometimes presented the issue as being only one of attaining a greater share of the allocation-rather than the issue being how to secure the right to any of the funds at all.

"Fernando Ferrer, the Bronx borough president, called for making health care more accessible to poor people and immigrants, for using more of the city's share of the nationwide tobacco settlement to treat the uninsured . . ."-New York Times, New York, 7 August 2001.

Several of the "needy" articles formulated their case for funds in relation to the plight of children. Children can be used as an effective "hook" within public portrayals of social problems by which to gain greater public recognition of and support for an issue. ${ }^{8}$ One Alabama columnist spoke fervently about the pressing need for funds to support the protection of children in the state foster care system, "with more than $\$ 3$ billion headed Alabama's way for the next 25 years, it looked as if Children First's [protective child services] promise finally would be fulfilled. Veterans of a long, difficult battle celebrated. Alabama foster parents, paid a measly $\$ 8$ a day to care for the state's youngest and most vulnerable citizens, would get a long-overdue increase."-Birmingham News, Alabama, 3 August 2001.

Several articles also outlined the extent to which hospitals deserved to receive MSA funds as a form of reimbursement for the uncompensated care that they provide.

"PinnacleHealth, which spends about $\$ 20$ million a year on uncompensated care, received $\$ 237,715$-about $10 \%$ of what it spends in uncompensated care each month. While this is only a fraction of what the health system spends, hospital officials are grateful." Harrisburg Patriot-News, Pennsylvania, 16 August 2001.

Alongside articles that emphasised those in need or deserving of the MSA funds, other articles framed the money as "state funds" and asserted that the money offered a unique opportunity for the economic advancement of the state, particularly in relation to the development of new industries.

"The tobacco settlement has provided $\$ 100$ million in funding for Pennsylvania to invest in the field of biotechnology this fiscal year in its effort to become the nation's leader in the innovative field." - Norristown Times Herald, Pennsylvania, 2 August 2001.

Some articles also presented the new funds for the state in relation to the possible opportunity to gain additional federal funding.

"Musgrove wants to use the tobacco money to attract additional federal dollars, thus freeing up state general funds for pay raises and state health insurance." Jackson Clarion-Ledger, Massachusetts, 19 August 2001.

Still other articles lent support to the application of MSA funds to capital projects that were presented as offering long term economic opportunities for the state.

" . . \$6 million for the first phase of a $\$ 150$ million water system . . .to provide infrastructure needed to support economic development. It will enhance public health, provide better firefighting ability and help ease the burden of federal and state monitoring requirements." Orangeburg Times and Democrat, South Carolina, 11 August 2001.

Another key component to the reporting of the allocation of the MSA funds were the petitions made of the funds on behalf of one or another state "crises". Nursing shortages, hospital operating deficits, high prescription costs, and health and safety issues such as contaminated waterlines were all pitted against the MSA funds as a matter of urgency and well being for the state. The portrayals of state crises were not, however, always as specific as those just discussed. The discussion of such crises in relation to the MSA funds covered both specific pressing state level demands as well as fairly general budgetary shortfalls.

\section{"Holden wants to use some of the tobacco money to help pay off a $\$ 300$ million budget deficit." - St Lovis Post Dispatch, Missouri, 10 February 2001.}

\section{"The Senate, ending the longest legislative session in state history, voted 20-9 in favor of a budget which uses $\$ 560$ million of the state's tobacco settlement money to balance the books." - Spartanburg Herald-Journal, North Carolina, 13 July 2001.}

Even when a particular issue was not identified, the recipient of the funds (in this case general budgetary funds) was given priority over the actual source of funding within coverage. 


\section{What arguments were used to make claims on MSA funds?}

Our analysis identified a tendency for articles to focus strongly on the funding needs of the particular substantive issue at hand. Articles highlighted the pressing need of a particular cause on whose behalf MSA funds were being claimed, rather than a rounder discussion of overall allocation. This focus underpinned a strong explanatory or persuasive element to the writing in many of the articles, such that the central issue was one of justifying levels of allocation to a particular cause. In some instances, it actually seemed as if the strength of the claims reflected the lack of any detailed description of why the money should be allocated to particular causes. Rather, some articles relied on the legitimacy of the claim being evident in the nature of cause itself, such that the issue becomes one of facilitating the use of available funds for self evident "good".

An alternative approach taken in several articles was to draw vivid illustrations of the conditions faced by particular groups, such that the pressing needs of the subgroup were clearly expounded. The following quote sets up a choice between eating and caring for one's health as part of an appeal to appropriate MSA funds to cover prescription drug benefits for seniors. "Drug costs sometimes force middle-income seniors to make hard choices between whether to buy food or fill a prescription."-Today's Sunbeam, New Jersey, 11 August 2001. In relation to the same issue, the Philadelphia Inquirer quoted Republican Patricia Vance as saying that these "Pennsylvanians need our help now, not later"-31 January 2001.

The needs of the particular subgroup were often illustrated through the use of emotive, personalised stories. The following example of the difficulties associated with prescription drug costs includes reference to an "obscene" situation in which people are forced to "beg" for the drugs that they need.

"But 72-year old Nick Canaday of Seattle heard the stories from his friends, and they remain all too real. "They skip their prescriptions, they beg their doctors for samples. That's obscene!" he said."-Yakima HeraldRepublic, Washington, 12 February 2001.

Beyond stressing the need associated with particular causes, some articles made more direct claims on the MSA funds on behalf of particularly deserving topics. Many such articles dealt with spending funds on health care. Articles that employed either the "needy" or the "deserving" frame also frequently asserted that the particular issue was covered in the remit of the settlement agreement.

"The administration shouldn't delay any of the national tobacco settlement money from getting to the cashstrapped agencies it was intended for to pay for badly needed children's programs." - Birmingham News, Alabama, 20 August 2001.

In sum, articles that focused on claiming funds for particularly needy causes or deserving groups such as prescription drugs for senior citizens, health care for children, and reimbursing hospitals for caring for the uninsured tended to focus on the particular issue at hand, utilising various techniques to highlight the particular issues as appropriate priorities for the spending allocations.

Other articles illustrated the legitimacy of a particular claim by making reference to the fact that any financial "need" actually exceeds the scope of the MSA funding. For example, articles that focus on hospital reimbursement often pointed out that even with the MSA funds, the existing shortfall would not be completely addressed.

"The \$114,119 the state gave St. Joseph Medical Center as part of Pennsylvania's tobacco settlement does not come close to covering the facility's annual cost for giving uncompensated care, but hospital officials are not complaining. Pennsylvania's first payout to hospitals [comes] from an $\$ 11.3$ billion settlement with cigarette manufacturers ..."-Reading Eagle, Pennsylvania, 19 August 2001.

Such coverage positions hospitals as being in dire financial situations because of their provision of uncompensated treatment. Journalists present hospital officials' "gratitude" for the additional funds, while also reinforcing that even these additional funds will not be adequate to meet the costs.

There was also a tendency for articles to make reference to the total amount of money associated with the MSA-either at the state or the national level.

"Over the next 25 years, Alabama will reap $\$ 3$ billion from tobacco companies ..."-Birmingham News, Alabama, 7 August 2001.

"The money would come from the state's $\$ 11.3$ billion share of the nationwide tobacco settlement." Bucks County Courier Times, Pennsylvania, 30 January 2001.

Referring to the size of the entire settlement may serve to minimise the appearance of the amount being requested for a particular cause. Articles framed requests for funds as being relatively unproblematic to the extent that they called only on a "fraction of the [state's] share of the national tobacco litigation settlement."-Charlotte Observer, North Carolina, 2 February 2001.

Other articles painted a bigger picture, and framed the discussion in relation to some ideological objective that might be sought through the application of these funds. The prime example of this were articles in which spending on a particular cause was framed as being central to a process of state development. Unlike the "needy" articles, those focusing on state development tended not to emphasise any particular connection of development plans to the purpose of the MSA. Rather, any potential financial advantages resulting from the allocation of these funds were presented as being of central concern.

\section{"Hoping to position Pennsylvania for the next great eco- nomic wave, Gov. Tom Ridge has added a $\$ 90$ million initiative to his plan for the tobacco settlement proceeds that would help pay for three regional life science greenhouses." - Sunday Patriot-News, Pennsylvania, 4 February 2001.}

Articles that focused on the potential for MSA funds to be applied towards state development provided little rhetoric to justify spending decisions. Instead, these articles asserted the right of the state government to spend its funds in any way that it sees fit.

Likewise, articles discussing the application of MSA funds to particular urgent state needs (such as new waterlines because of uranium contamination) spent little, if any, time discussing the long term merits of the application of funds to such an issue. The funds were simply conceptualised as being available resources that would allow the state to plug a particular hole.

"The uranium thing is such an obvious human problem. It's the type of problem that tends to draw a quicker response than some of the habitat-related issues." Greenville News, South Carolina, 11 August 2001 
" . . . the state should immediately spend $\$ 36$ million a year or more from the $\$ 11$ billion tobacco settlements to increase the income levels for PACE (prescription drug benefits) ...We have too many senior citizens who can't afford prescription drugs. We have to act now." - Patriot News, Pennsylvania, 12 December 2001.

State "crises" articles were frequently presented in such a way as to portray the allocation of MSA funds as a "non-issue". The articles highlighted the availability of MSA money, and implied that any opposition to the allocation of "extra" funds in the state coffers as a way of averting one disaster or another would be inconceivable. Such "crises" articles frequently implored decision makers to act in unusual ways in order to address an unusual necessity-to forgo the normal rules of spending if necessary to meet the particular demands being presented. Several such articles employed battle terminology with words such as "fighting", "mission" or even "blitzing a silent killer" (Baltimore Sun, Maryland, 5 February $2001)$ to stress the urgency of particular issues.

Discussions of spending MSA funds on shoring up current budgetary needs sometimes built on a description of the money as a "windfall" for the state. In such instances, funds were portrayed as an unexpected extra, and thus not reflecting any real loss should they be poured into the budget. The budgetary overspend that such spending necessarily implied was sheltered by portrayals of the funds as a "gift" or "free money".

"The final plan to spend the state's nearly $\$ 11.3$ billion windfall from the tobacco industry will include elements of proposals from both chambers." - Bucks County Courier Times, Pennsylvania, 4 February 2001.

The application of a "windfall" frame in such instances might be understood as a defence against the public criticism that often follows budgetary shortfalls. Indeed, there were several articles that were critical of the allocation of MSA funds to filling budget gaps. One newspaper summed up the allocation of MSA funds to general budgetary spending in the following manner.

" . . squander[ing] all the tobacco money and fail[ing] to invest in our children and the future of our state." - Anderson Independent Mail, South Carolina, 8 August 2001.

Such references to the MSA funds as a "windfall" for the state, rather than as a reimbursement for tobacco related costs, were also fairly common within the coverage, discussing particular issues such as healthcare and economic development. For example, one article from the Missoulian of Montana in which the issue of affordable health care was being discussed lends support to a proposal to " . . .tap into some of the interest revenue from the tobacco trust" (28 January 2001).

Thus, discussions of spending on state crises fell into two distinct types-budgetary crises, and all others. While both were portrayed as superceding any other need to which the MSA funds might be applied, each frame was presented in quite different ways. The articles that discussed budgetary crises highlighted the extent to which the MSA funds were additional, and thus neither anyone's prerogative, nor anyone's loss, should they be applied to the state deficit. On the other hand, the articles that focused on other kinds of state crises (such as nursing shortages or possible health hazards) tended to minimise any discussion of the source of the funds, and rather framed the discussion around the opportunity and absolute necessity to address the particular crisis at hand.
"Health officials begin campaigns to fight colorectal disease. "We've got to save lives." State plans to use nearly $\$ 16$ million in tobacco money. . ..health officials are launching a statewide blitz to fight a silent, often overlooked killer."-Baltimore Sun, Maryland, 5 February 2001.

In summary, there were several key strategies employed to support claims being made for MSA funds. Articles tended to focus on the urgency of the cause itself, rather than the issue of fund allocation, they used vivid, personalised illustrations of need, and emphasised the extent to which needs exceeded the requests being made of the MSA funds. Presenting MSA funds as a "windfall", and making reference to the amount of the entire settlement, were additional devices employed to strengthen claims.

\section{DISCUSSION}

Media advocacy is a proactive, concerted effort to harness energies toward a specific subject area through the use of the mass media. The process involves working directly with the producers of local news to influence the level of attention that is afforded to specific concerns and their potential solutions, and furthermore to direct "special attention to counteracting or reframing any strengths of their opponents' arguments". ${ }^{.8}$ Our analysis of press coverage of allocation of MSA funds revealed a newsworthiness for the issue of the MSA funds themselves-separate from any controversy as to whether funds are being spent on tobacco control. These data strongly suggest that, at least in some instances, the debate over MSA allocation has quickly moved beyond the extent to which the funds should be allocated to tobacco control efforts. News coverage of MSA allocation outside of tobacco control was rather focused on the presentation of justifications for the appropriation of funds towards various worthy causes. Our analysis also suggests that the arguments being put forward in these articles rested on an assumption that the funds both could and should be shared beyond tobacco control or even health and health care projects.

If tobacco control is to be more successful in making claims for funds such as those from the MSA, perhaps it can make better use of some of the rhetorical strategies that are employed in relation to these other issues. It may not, in fact, further the cause of tobacco control funding to continue to assert the claim for MSA funds on the basis that this is what the MSA was supposed to fund. It may be more effective to simply assume the right to the funds and then to use media advocacy to prioritise the pressing need for additional resources for tobacco control. Furthermore, tobacco control might benefit from framing claims for funds in relation to heart wrenching stories, as well as working to demonstrate how the allocation of MSA funds to tobacco control might benefit the state's overall-and economic —wellbeing.

Since tobacco control harm takes years to ameliorate, the challenge must be to assert our claims strongly alongside those issues whose effects are more immediate (such as balancing the budget) or are more likely to be politically expedient (such as providing prescription drugs for the elderly). As the MSA funds are now conceptualised from within the realm of state politic, in reasserting a claim to MSA funds and opposition to more popular causes, so tobacco control advocates may risk being portrayed as uncompromising zealots. Tobacco control may actually benefit from acknowledging and being seen to understand competing claims on such funds.

We have discussed different ways in which the allocation of funds to particular non-tobacco control areas were justified through framing the news stories either in relation to assisting particularly needy or deserving groups, advancing state development or addressing state crises. In addition, our analysis 
revealed rhetorical devices that ran between these diverse perspectives. For example, all such articles clearly make the assertion that there are issues that are just as (if not more) pressing as tobacco control at the state and local level. Thus, in various ways, which are often implicit, the articles serve as declarations of the legitimacy of various causes (be it prescription drugs for seniors, laptops for legislators, biotech greenhouses or health insurance for the unemployed) in relation to the MSA funds. Although writers did not always align the issues being discussed in relation to the original grounds of the settlement, the call upon these funds is clearly demonstrated in all of the articles. Thus, in various ways, the media coverage of MSA allocation can contribute to the establishment of seemingly innocuous issues as formidable "opponents" for tobacco control.

An additional concern to emerge from this consideration of news coverage of the allocation of MSA funds was the extent to which these resources are being conceptualised as "tobacco money", thus potentially associating the tobacco industry with positive contributions to state or community welfare.

\section{"The plan would require the board of the Health and Wellness Trust Funds, which oversees $25 \%$ of the $\$ 4.6$ billion the state will receive from cigarette makers, to provide money to programs to help seniors buy prescrip- tion drugs." - Winston-Salem Journal, North Carolina, 28 April 2001}

Such references portray the funds as if they are the result of a corporate gift, rather than as reimbursement for particular societal costs that result from corporate wrongdoings.

"Cities and counties are lining up for a chunk of South Carolina's lucrative settlement with the tobacco industry. The municipalities have submitted 214 applications as they seek to build new roads, fiber optic lines and water and sewage treatment plants in economically depressed areas." - Herald-Journal, South Carolina, 18 October 2001.

Whenever additional hospital resources, prescription drug benefits, teachers' pay increases or other areas of new spending on key social concerns are presented as coming from "tobacco money" without an associated statement as to the cause and objectives of the settlement, so coverage may serve to support the public relations strategies of the industry which has long used community donations as a means of improving corporate image. This study suggests that the moral identity of the tobacco industry may be inadvertently being boosted after years of work on the part of tobacco control advocates to undermine such an identity in the eyes of the US public.

Instead of press coverage presenting an image of the tobacco industry as a powerful force that duped the US public and caused untold suffering, coverage of MSA allocation potentially frames the tobacco industry as positively contributing to solving pressing problems which threaten communities, as well as the most vulnerable members of our population. Thus, the coverage of the settlement monies serves to cast the industry in a positive light. Such publicity may also distract the public from why the monies were collected in the first place. To the extent that the conceptualisation of the tobacco companies as "good corporate citizens" is supported by press coverage of the MSA, so the coverage serves to damage, rather than to contribute to tobacco control measures.

It is our hope that this analysis might prove insightful for those involved in seeking funds for tobacco control from the MSA or other unmarked government funding streams, and for those who might be in the position of negotiating similar settlements or funding streams from governments or the tobacco

\section{What this paper adds}

Tobacco control has not received the level of additional funding from Master Settlement Agreement (MSA) payments to the states that many had hoped. Only three states currently (as of mid 2002) allocate the recommended $20-25 \%$ of MSA funds to tobacco control programmes (the minimum recommended level as determined by the Centers for Disease Control and Prevention), and the majority of states actually currently allocate less than half of this. Numerous social science and public health studies have established that the news media plays a key role in framing issues such as the allocation of funds for both the public and policy. The identification of newsworthy non-tobacco control claims on MSA funds and the examination of the presentation of such funds in the US press will provide important insight for securing future funds for tobacco control.

This qualitative textual analysis of newspaper coverage of MSA spending outside of tobacco control shows the extent to which the funds were quickly formulated for the public and policy makers as state fodder. The analysis illustrates a wide range of alternative applications for the MSA funds that cluster around three main themes of securing funds for the needy, funds for state development or funds for a crisis. Furthermore, we identify several rhetorical devices employed in the press coverage to lend support to these claims. Since tobacco control harm takes years to ameliorate, the challenge must be to assert our claims strongly alongside those issues that might pay earlier dividends or be more politically expedient.

industry in the future. Our data suggest that the funds have been quickly formulated (at least by the press) as general state funds. Further, the presentation of allocation decisions through the media supports the allocation of funds to issues that can be constructed with a more immediately emotive rationale. Thus, we suggest that considerable caution is required in pursuing settlements with the industry where the objective is better funding for tobacco control efforts, as our data would suggest that such funds will be difficult to wrest away from claims made on behalf of other worthy causes. This is particularly relevant when aligned with the possibility that the tobacco industry may actually gain positive publicity from news coverage of settlement spending.

\section{ACKNOWLEDGEMENTS}

This project is part of the State \& Community Tobacco Control Interventions Research Initiative funded by the National Cancer Institute's Tobacco Control Research Branch, grant R01 CA86273-01.

\section{Authors' affiliations}

K M Clegg Smith, University of Illinois at Chicago, Chicago, Illinois, USA

M A Wakefield, Centre for Behavioral Research in Cancer, The Cancer Council Victoria, Carlton, Victoria, Australia

M Nichter, Department of Anthropology, University of Arizone, Tucson, Arizone, USA

\section{REFERENCES}

1 Campaign for Tobacco Free Kids. Rankings of state funding for tobacco prevention. http://www.tobaccofreekids.org/reports/ settlements/2002mid/spendingchart.pdf. 2002

2 Stevens C. Designing an effective counter advertising campaign California. Cancer 1998;83:2736-41.

3 Chapman S. The news on tobacco control: time to bring the background into the foreground. Tobacco Control 1999;8:237-9.

4 Malone R, Boyd E, Bero L. Science in the news: journalist's constructions of passive smoking as a social problem. Social Studies of Science 2000;30(4): 1-23

5 Wakefield $M$, Flay $B$, Nichter $M$, et al. Role of media in influencing trajectories of youth smoking. Addiction 2003;98:79-103. 
6 Menashe C, Siegel M. The power of a frame: an analysis of newspaper coverage of tobacco issues - United States, 1985-1996. Journal of Health Communication 1998;3:307-25.

7 Altheide $\mathbf{D}$. The news media, the problem frame, and the reproduction of fear. The Sociological Quarterly 1997;38:647-68.

8 Best J. Troubling children: studies of children and social problems. New York: Aldine de Gruyter, 1994.

9 Tuchman G. Making news. New York: The Free Press, 1978.

10 Lima J, Siegel M. The tobacco settlement: an analysis of newspaper coverage of a national policy debate, 1997-8. Tobacco Control 1999:8:247-53.

11 Cummings KM, Sciandra R, Markello S. Impact of a newspaper mediated quit smoking program. Am J Public Health 1987;77: 1452-3.

12 Leask J, Chapman S. An attempt to swindle nature: press reportage of anti-immunisation, Australia 1993-97. Aust NZ I Public Health 1998;22:17-26

13 Poyant JC, Siegel M. The tobacco settlement: an analysis of newspape coverage of a national policy debate, 1997-98. Tobacco Control 1999;8:247-53.

14 Jernigan DH, Wright PA. Media advocacy - lessons from community experiences. Journal of Public Health Policy 1996;1 1:306-30.

15 Russel A, Voas RB, Dejong W, et al. MADD rates the states: a media advocacy event to advance the agenda against alcohol-impaired driving Public Health Reports 1995;110:240-5.

16 Wallack L, Dorfman L, Jernigan D, et al. Media advocacy and public health: power for prevention. Newbury Park, California: Sage, 1993.

7 Spector M, Kituse J. Constructing social problems. Menlo Park,

California: Cummings Publishing Company, 1977

18 Chapman S. Advocacy in public health: roles and challenges. Int J Epidemiol 2001;30:1226-32.

\section{The Lighter Side}

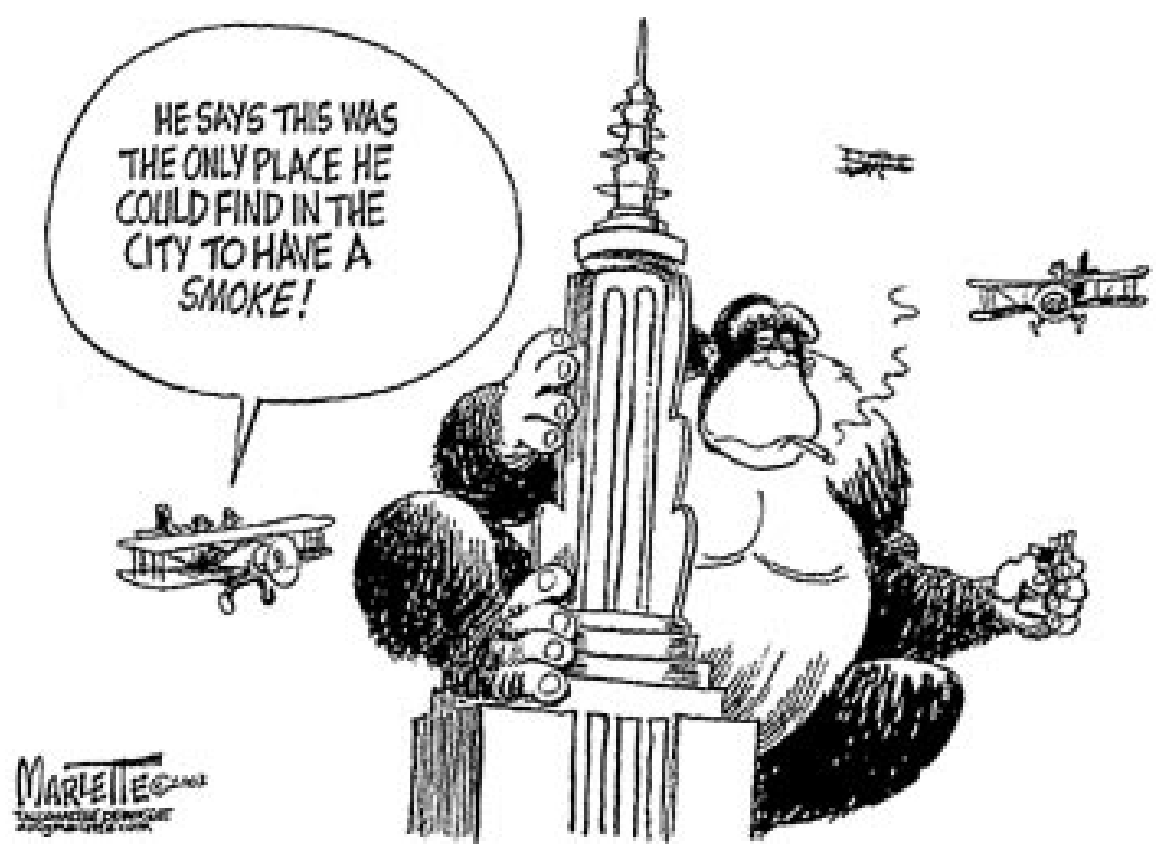

(c) TheTallahassee Democrat, 2003. By Doug Marlette. 